\title{
Knowledge and perception of mothers and caregivers on childhood diarrhoea and its management in Temeke Municipality, Tanzania
}

\author{
K.D. MWAMBETE ${ }^{*}$ and R. JOSEPH ${ }^{2}$ \\ ${ }^{1}$ Department of Pharmaceutical Microbiology, University of Health $\mathcal{E}$ Allied Sciences, School of Pharmacy, P. O. \\ Box 65013, Dar es Salaam, Tanzania \\ ${ }^{2}$ Muhimbili National Hospital, P. O. Box 6500, Dare es Salaam, Tanzania.
}

\begin{abstract}
Diarrhoea is an increase in volume of stool or frequency of defecation. It is one of the most common clinical signs of gastrointestinal diseases, but also can reflect primary disorders outside of the digestive system. This cross-sectional descriptive survey was conducted in Temeke Municipality, Dar es Salaam over a 4-month period to investigate on knowledge and perception of mothers/caregivers of underfives on childhood diarrhoea. Specifically, the study focused on frequency of diarrhoeal episodes and their risk factors as well as effectiveness of traditional remedies used for its management prior to seeking medical attention. A semi-structured questionnaire was used for data collection, through which a total of 161 mothers were interviewed. Of those, 74 (46\%) had female and $87(54 \%)$ had male underfives with median age of 2-years. Frequency of diarrhoeal episodes was high among the underfives and was comparable between females and males (87 vs $74 ; P<0.05)$. Medicinal plants were the most common traditional remedies employed by majority $(71 \%)$ of the interviewees, which have been purported to be effective in management of childhood diarrhoea. Guava (leaves and fruits) was the most commonly used remedy in the treatment of diarrhoea. Mothers' knowledge on predisposing factors of childhood diarrhoea was poor, which was directly correlated with education level. Only about one-third of the respondents (31\%) were aware of risk factors for childhood diarrhoea that cited poor sanitation and water as the main factors. Diarrhoeal episodes were perceived wrongly as normal growth stage and that were caused by several other "illnesses". It is important that further studies on traditional remedies should be carried out to validate their usefulness in the treatment of childhood diarrhoea.
\end{abstract}

Key words: childhood diarrhoea, management, treatment, traditional remedies, Tanzania

\section{Introduction}

Diarrhoea affects people of all ages, and it is characterized by loose and watery stools occurring more than three times in a day. It is a common problem that usually lasts for 24 hours or more and sometimes spontaneously disappears without any special treatment. Some of the major causes of diarrhoea are bacterial infections due to Campylobacter, Salmonella, Shigella, and Escherichia coli. Viral infections such as rotavirus, cytomegalovirus, Norwalk, hepatitis, and herpes simplex viruses also play a major role in diarrhoeal problems among both children and adults (Fekety, 1997; Dupont, 1997). Similarly, food intolerances and intestinal parasites may also cause diarrhoea. Reactions to medicines such as antibiotics, and antacids containing magnesium may also attribute to diarrhoea. Chronic diarrhoea can be caused by chronic ethanol ingestion, though this kind of diarrhoea is atypical among children under 5-year-old (Longstreth et al., 2006).

Approximately 2.2 million people in developing countries, most of them children (90\%), die every year from diseases associated with lack of access to safe drinking water, poor

\footnotetext{
Correspondence: Kenedy D.Mwambete; E-mail: kmwambete@muhas.ac.tz
} 
sanitation/hygiene and overcrowding. Of the 6.6 million deaths among children aged 28 days to five years, 1.7 million (26\%) die from diarrhoea because of dehydration (Claeson \& Merson, 1990; Snyder \& Merson, 1982). Diarrhoea kills more young children around the world than malaria, acquired immunodeficiency syndrome (AIDS) and tuberculosis (TB) combined (WHO, 1997). The situation in Tanzania is not distinct from that of other developing countries; and thus diarrhoea is an important public health problem as result of poor and insufficiency of water supply system (WHO, 1997, 2000). Only minority of Tanzania citizens have access to clean and safe water.

Deaths in diarrhoeal cases are largely attributable to it complications which include dehydration, impaired renal function, acidosis, secondary infections and disseminated intravascular coagulation as well as hypotension and fainting (Gabr, 1983). The alarming situation is aggravated by delay in initiation of treatment and inadequate rehydration resulting in high morbidity. Conventional treatment of diarrhoea includes endoscopic examination of the colon with flexible sigmoidoscopy and colonoscopy, which allow direct examination of the bowel mucosa with the ability to obtain biopsies for microscopic evaluation (Scheidler \& Giannella, 2001). In most cases, replacing lost fluid to prevent dehydration is the only necessary treatment. However, sometimes diarrhoea is empirically treated with antibiotics prior initiation of an extensive workup (Fekety, 1997). Presumably, diarrhoea could be extricated by improving indigenous remedies and/or using them concurrently with conventional means for management of diarrhoeas.

This study therefore intended to assess the knowledge and perception of mothers/caregivers on childhood diarrhoea focusing on three main aspects viz. frequency of diarrhoeal episodes and their risk factors as well as effectiveness of traditional remedies used for its management prior to seeking medical attention.

\section{Materials and Methods}

\section{Study design}

It was a non-experimental descriptive cross sectional survey which was carried out during a 4-month period (February to May 2007) using face to face interview guided by a semistructured questionnaire. The study was conducted in Temeke Municipality, Dar es Salaam, Tanzania and it involved all mothers with underfives. Data records from census of 2002 were employed for random sampling of the localities that had high number of underfives in the study area, where a sample size of 196 was determined. However, a total of $161(83 \%)$ mothers were interviewed of the expected study population. Inclusion and exclusion criteria for participants were all willing and unwilling mothers of underfives, respectively. The interviews were conducted at household settings by pre-trained researchers.

\section{Data collection}

The main issues that were addressed were socio-demographic characteristics of the interviewees, frequency of diarrhoeal episodes among the underfives and measures adopted to curb diarrhoea outbreaks. To instigate further on the measures adopted against diarrhoea, the interviewees were asked what kind of measures were taken to alleviate diarrhoea before presenting to any health facility. Furthermore, they were also enquired on traditional methods/remedies they knew and utilized in management of diarrhoea. In order to investigate on the mothers' knowledge on diarrhoea, they were asked on the predisposing factors of diarrhoea, and what were the main sources of water they usually used and how 
they treated it prior to administering to underfives. The study also assessed the mothers' knowledge on management of diarrhoea in respect of their educational levels. The effectiveness of the traditional remedies was also investigated by enquiring on time-lapse to get relief upon administration of the remedies and possible adverse effects if any. To further look into the effectiveness of the traditional remedies, the respondents were asked whether there were recurrences of diarrhoeal episodes upon utilization of the remedies.

\section{Data analysis}

Data were cleaned, that is irrelevant information were omitted on daily bases before coding and entering them into a database. The coded information was statistically analyzed for frequency, association and correlation using the Statistical Package for the Social Sciences (SPSS+ version 15.0, 1999) software (SPSS Inc., Chicago, IL). Significance level was set at $\mathrm{p}<0.05$.

\section{Ethical considerations}

The study received ethical approval from Muhimbili University of Health and Allied Sciences Research Committee. Both informed verbal and written consents were sought from each participant. The objectives of the study were elucidated and sufficient time was allocated for the interviewees to decide whether to participate in the study or not. The interview process was conducted with adequate confidentiality by approaching and interviewing each participant separately, and without revealing names of the interviewees.

\section{Results}

\section{Socio-demographic characteristics of the study population}

A total of 161 mothers (age=16-52 years) distributed within 18 localities of the Temeke Municipality were interviewed. Of these $74(46 \%)$ and $87(54 \%)$ had female and male underfives, respectively with median age of 2 years. Of the 161 interviewed mothers, 33 $(20.5 \%)$ were illiterates and none had university education or its equivalent (Table 1). A number of children negatively correlated with the mothers' level of education (Pearson correlation, $\mathrm{r}=-0.312 ; P<0.001)$; while positively correlated with the parents' ages $(\mathrm{r}=0.788$; $P<0.001)$.

Table 1: Socio-demographic characteristics of the study population categorized by diarrhoeal episodes among the underfives

\begin{tabular}{lcccc}
\hline Variable & \multicolumn{4}{l}{ Frequency of diarrhoeal episodes (\%) $\mathbf{n}=\mathbf{1 6 1}$} \\
\cline { 2 - 5 } $\begin{array}{l}\text { Several } \\
\text { time/day }\end{array}$ & Once/week & $\begin{array}{l}\text { Several } \\
\text { times/week }\end{array}$ & Occasionally \\
\hline Parent's education & 12 & 9 & 11 & 1 \\
None & 25 & 22 & 40 & 11 \\
Primary & 9 & 14 & 3 & 2 \\
Secondary & - & - & 2 & - \\
Tertiary & 3 & 3 & 4 & - \\
\hline Age (years) of mother/caregiver & 28 & 9 & 18 & 6 \\
16-21 & 11 & 17 & 12 & 7 \\
$22-27$ & 10 & 6 & 6 & 1 \\
$28-33$ & & & &
\end{tabular}




\begin{tabular}{lcccc}
$40-45$ & 4 & 7 & 6 & - \\
$46-52$ & - & 3 & - & - \\
\hline Sex of the child & & & & 8 \\
Females & 21 & 18 & 27 & 6 \\
Males & 25 & 27 & 29 & $14(8.7)$ \\
\hline Total & $46(28.5)$ & $45(28.0)$ & $56(34.8)$ & \\
\hline
\end{tabular}

Perception and knowledge of mothers/ caregivers on childhood diarrhoea

All interviewees agreed that their children have had diarrhoea in their life-times (Table 1). Statistically no significant differences between male 87 (54\%) and female 74 (46\%) underfives were observed with respect of diarrhoeal episodes $(P=0.157)$.

The source of water for routine domestic for the majority $(56.5 \%$; $\mathrm{N}=91)$ was wells. Other sources were tap water $(\mathrm{N}=51 ; 31.7 \%)$ and both tap water and wells $(\mathrm{N}=19 ; 11.8 \%)$. Eighty-two percent (132) of the mothers admitted to have not observed any precaution during preparation of their children's meals or cleanliness of utensils. A few 24 (15\%) said they usually disinfect the utensils by boiling and $2(1.2 \%)$ use treated water. Caregivers/mothers' responses on knowledge of predisposing factors of diarrhoea are summarised in Table 2. About one third (33\%) of the mothers/caregivers were not aware of the risk factors for diarrhoea and $46(30 \%)$ described it as a normal growth stage. Of 161 respondents, only 62 $(31 \%)$ provided correct responses in respect to causes of diarrhoea.

Table 2: Perceived causes of childhood diarrhoeas among mothers and caregivers

\begin{tabular}{|c|c|c|c|c|c|c|c|}
\hline \multirow{2}{*}{$\begin{array}{l}\text { Parents' } \\
\text { education }\end{array}$} & \multicolumn{6}{|c|}{ Causes of Diarrhoea (\%) } & \multirow{2}{*}{$\begin{array}{c}\text { Total } \\
(\%)\end{array}$} \\
\hline & Growth stage & Illness & Water & Allergy & Poor sanitation & Unaware & \\
\hline None & $13(8.1)$ & $6(3.7)$ & $4(2.5)$ & $0(0.0)$ & $3(1.9)$ & $7(4.3)$ & $33(20.5)$ \\
\hline Primary & $23(14.3)$ & $15(9.3)$ & $7(4.3)$ & $4(2.5)$ & $9(5.6)$ & 38 (23.6) & $98(60.9)$ \\
\hline Secondary & $10(6.2)$ & $8(5.0)$ & $1(0.6)$ & $0(0.0)$ & $0(0.0)$ & $8(5.0)$ & $28(17.4)$ \\
\hline Tertiary & $0(0.0)$ & $2(1.2)$ & $0(0.0)$ & $0(0.0)$ & $0(0.0)$ & $0(0.0)$ & $2(1.2)$ \\
\hline Total & $46(28.6)$ & $31(19.2)$ & $12(7.4)$ & $4(2.5)$ & $15(9.3)$ & $53(33.0)$ & $161(100)$ \\
\hline
\end{tabular}

Because of an equal distribution of population in respect of water utility/sources for domestic uses; the study could not establish association between the water sources and occurrence of diarrhoeal episodes. However, 102 (63\%) respondents purported to have been using boiled water, though they experienced more diarrhoeal episodes compared to the rest (Figure 1). 

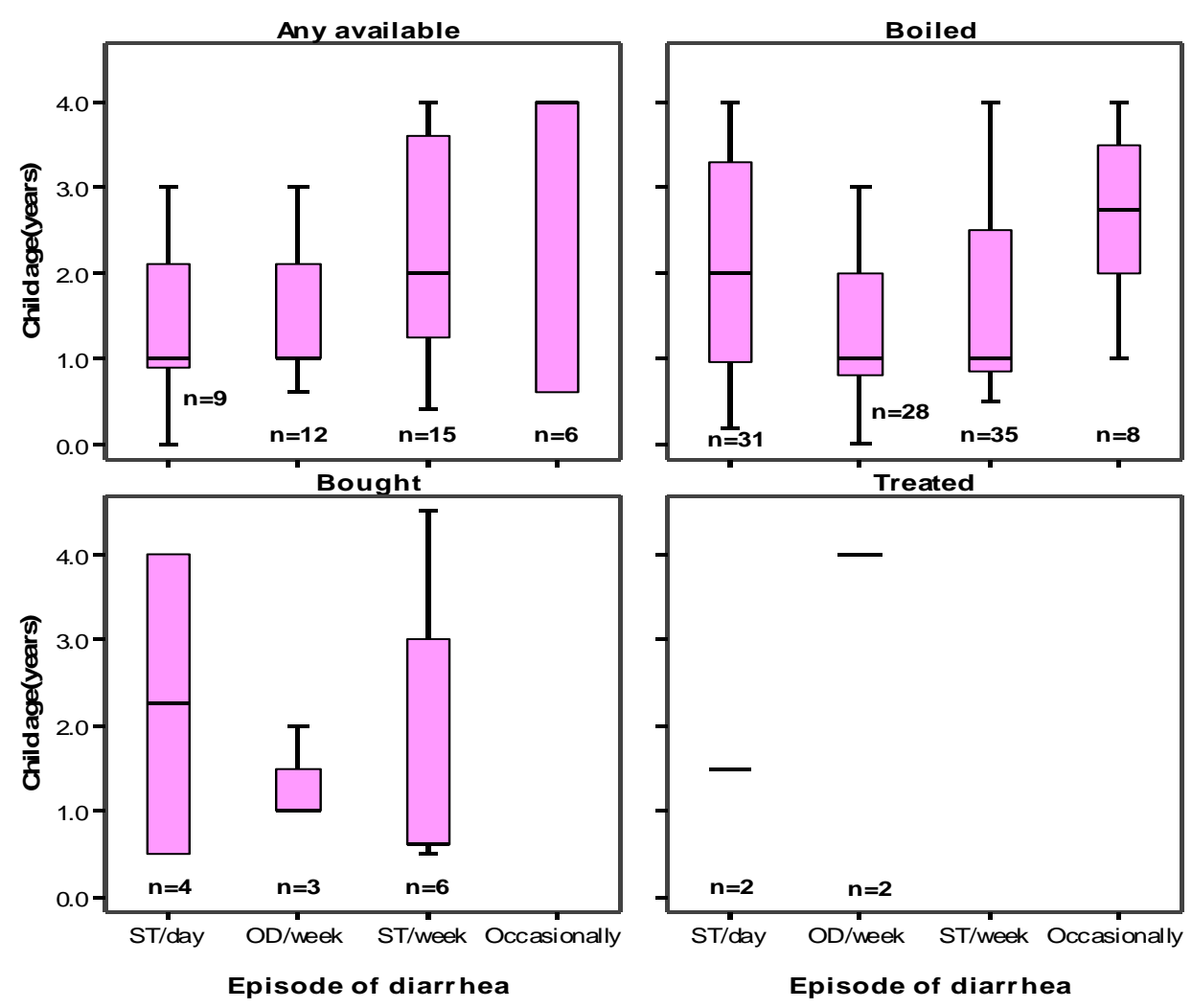

Figure1: Frequency of diarrhoeal episodes among underfives in relation to water utility/sources (OD-once per day; ST-several time per day)

\section{Frequency of diarrhoeal episodes among the study population and its management}

When asked what measures do they take when such episodes of diarrhoea occur, 60 (37.3\%) admitted to wait for some times until when deems necessary to take the child to a healthcare facility. About one-third (61.5\%) of the respondents managed the illness domestically, whilst only $1.2 \%$ said to usually rush to nearby health facilities.

Several traditional remedies used in management of diarrhoea were mentioned. However, $46(28.5 \%)$ interviewees could not state any traditional means of controlling diarrhoea (Table 3). Guava (Myrtaceae psidium guayava), locally known as Mpera was the most frequently mentioned remedy $(\mathrm{N}=45 ; 28 \%)$ respondents. Other local remedies included leaves or fruits of Mangifera indica, Annona senegalensis, Anacardium accidentale, Punica granatum, Solanum incanum, Cajanus cajani and Tamarindus indica. Wheat flour, mixture of water and ash and green beads were also mentioned as effective means of alleviating diarrhoea. These were boiled, and then upon cooling, the liquid was administered orally to children, while the beads were worn on arms. The study also assessed the mothers' knowledge on management of diarrhoea with respect to educational levels. Results showed that, 70 (43.5\%) respondents entirely relied on traditional remedies for management of diarrhoea. Of those $17(24.3 \%)$ had no formal education while $37(53 \%)$ and $11(15.7 \%)$ had primary and secondary education, respectively. Metronidazole (flagyl) and oral rehydration solution (ORS) were cited by 35\% and $10.5 \%$, of respondents as the most effective conventional chemotherapeutic agents most frequently used in resolving diarrhoeal problems (Table 3). 
Table 3: Ten conventional " therapeutic agents" most frequently used for treatment of childhood diarrhoea

\begin{tabular}{|c|c|c|}
\hline Treatment & Frequency $(n=88)$ & Percentage \\
\hline Erythromycin and Metronidazole & 12 & 13.6 \\
\hline Metronidazole & 43 & 48.9 \\
\hline Metronidazole and flour & 6 & 6.8 \\
\hline Oral Rehydration Solution & 17 & 19.3 \\
\hline Paracetamol & 4 & 4.5 \\
\hline Salt & 2 & 2.3 \\
\hline Erythromycin and Chloramphenicol & 4 & 4.5 \\
\hline
\end{tabular}

\section{Effectiveness of the traditional remedies on controlling diarrhoea}

Majority of the respondents 124 (77\%) were affirmative on the effectiveness of the traditional remedies that were used for management of diarrhoea. Most $(79 \%)$ of the caregivers/mothers said usually the diarrhoea subsides completely following use of traditional remedies. Twenty-nine (18\%) were not sure while $5(3.1 \%)$ said it recurs rarely. Of those who claimed to have had never experienced recurrences of diarrhoea upon using the traditional remedies, 71 (56\%) fetched water from wells, $43(34 \%)$ used tap-water while $13(10 \%)$ used water from both sources. The majority $(84 \%)$ of the respondents declared that the traditional remedies had no side effects, while $14(8.7 \%)$ said they did not know. Only $7.3 \%$ claimed to know some adverse effects of using traditional remedies. The commonly mentioned adverse effects included nausea, vomiting, stomachache and lassitude.

\section{Perceived implications of diarrhoea among underfives}

About $81 \%$ of the interviewees affirmed that their children had normal growth rates regardless of some diarrhoeal episodes. While $29(18 \%)$ noticed that the children's growth rates were unusual. The abnormality was relatively more evident in males than females (20 against 9). Out of 29 respondents who admitted that their children growth rates were affected, $22(76 \%)$ said the children usually get diarrhoea at least once in a week-time, whilst the $6(21 \%)$ said the underfives suffered from diarrhoea several times per week. A negative correlation (2-tailed), though not statistically significance $(\mathrm{r}=-0.05 ; P<0.531)$ was observed between growth status and diarrhoeal episodes among the underfives. Moreover, a positive correlation $(r=0.248 ; P<0.01)$ between diarrhoeal episodes and children's ages was eminent. Results have also revealed high rate of irrational use of antibiotics. Out of 88 respondents who apart from the traditional remedies employed other means to alleviate fever, $65(74 \%)$ used antibiotics or their combinations (Table 3). It was also uncovered that $13(8.1 \%)$ out of 161 interviewees had previously lost their children at different growing stages prior attaining 5 years of age; though the causes were not disclosed.

\section{Discussion}

The present study has demonstrated high frequency of diarrhoeal episodes among underfives in the study area, which is manifested by the fact that all the interviewees had experienced diarrhoea, which was occasionally perceived as normal growth condition. Currently, diarrhoea is one of the major killers of underfives in Tanzania and other Sub-Saharan Africa countries (Gascón et al., 2000; Mandomando et al., 2007; Hamer et al., 1998). As previously 
indicated, most of mothers empirically treat their children with first aids medicines, diarrhoea management inclusively, before seeking further medical attentions. This goes parallel with self-medication and use of some traditional remedies (Mandomando et al., 2007; Mahalanabis et al., 1996). Several reasons may explain this; firstly the unavailability and costs of medical services, which oblige most of the mothers to opt for alternative medicines and/or the fact that most mothers/caregivers would wait until the condition, worsen before seeking medical care at health facilities (Mahalanabis, 1996; HAI, 2007). Secondly, could be because of the demonstrated effectiveness of the traditional remedies in combating some common illnesses like diarrhoea (Shangali et al., 2008). The study has also showed that the interviewees opted for traditional remedies for management of diarrhoea irrespective of their awareness on the conventional therapies and education levels contrary to findings elsewhere (Mahalabis et al., 1996). For instance the use of wheat flour by respondents in management of diarrhoea is justified by the fact that addition of small amount of amylase from germinating wheat flour has demonstrated to be effective in controlling diarrhoea and enhancing macronutrients absorption in infants with acute watery diarrhoea (Mujibur et al., 1997).

Notwithstanding the realization of what to do whenever a child had diarrhoea, substantial knowledge-gaps existed among the interviewees regarding diarrhoeal predisposing factors, which may be one the major hindrances for adopting effective preventive and control measures. The fact remains that approximately $30 \%$ of the respondents regarded diarrhoea as part and parcel of normal growth process, an indicative of ignorance about the disease as consequence of illiteracy, because all schooled mothers did not give such remarks. The so-called "illness" which was also presumed to one of the predisposing factors for diarrhoea, may imply that for a sick child, diarrhoea is unavoidable. This perception prevails among several mothers/caregivers.

In line with previous studies, our findings depicted direct implication of environmental sanitation on diarrhoeal morbidity, which implies that children living in families that have access to good quality water supplies and latrine, experience less diarrhoeal episodes (Young \& Briscoe, 1987; Scheidler \& Giannella, 2001; Khalil et al., 2008). Unhealthy environment has been the main factor for causation of diarrhoeal diseases in several resources-limited countries (WHO, 1997, 2000; Gascón et al., 2000). For this reason, diarrhoea and dysentery have higher incidences among lower classes citizens that are ascribable to the poor state of physical environment in which they dwell (Young \& Briscoe, 1987; Mandomando et al., 2007). Additionally, poor methods of food handling, storage, source and use of unsafe water, as well as poor personal hygiene all contribute to the potential risk factors of developing diarrhoea. This can be partly be explained by the fact that although about two-thirds of the respondents used boiled water to attend to their children's needs, they experienced more diarrhoeal episodes in comparison to those who used treated or bottled water. The causative agents of diarrhoea were not investigated in the present study, that is whether the diarrhoeas were of bacteria, viral or any other origin, because of the nature of the study (household setting), which might be one of the drawbacks.

The observed reluctance of the caregivers and mothers to seek for health care services on regular basis needs to be addressed, because it has been demonstrated that usually children may asymptomatically harbour numerous enteropathogens whether they have diarrhoea or not (Hamer et al., 1998; Young \& Briscoe, 1987). Certainly this may also contribute to the diarrhoea-caused high morbidity and mortality among underfives, particularly in developing countries due to inaccessibility of health services. The importance of oral rehydration therapy (ORT) cannot be overemphasized because of its cost-effectiveness 
and being the simplest therapeutic intervention for the management of diarrhoea (Akpede \& Omotara, 1997; Zodpey et al., 1998). Therefore, prompt and accurate diagnosis coupled with timely initiation of ORT can attenuate the gravity of diarrhoeal problem. On the other hand, the irrational antibiotic usage observed among the underfives, raises a great preoccupation on the unpredictable disastrous consequences like development of antibiotic resistance (MacGowan, 2008).

In conclusion, medicinal plants were the most common traditional remedies employed by majority of the interviewees, which have been purported to be effective in management of childhood diarrhoea. Guava (leaves and fruits) was the most commonly used remedy in treatment of diarrhoea. Mothers' knowledge on predisposing factors of childhood diarrhoea was poor and was directly associated with education level. Diarrhoeal episodes were perceived wrongly as normal growth phenomenon and that were caused by several other "illnesses". The study recommends that the traditional remedies should be further investigated, since they are perceived to be helpful in resolving the childhood diarrhoeal episodes. Parallel to provision of sanitary education to mothers and caregivers of underfives, the necessity of attending clinics on routine-basis despite the absence of apparent health problems also needs to be emphasized.

Received 5 May 2009

Revised 8 December 2009

Accepted 9 December 2009

\section{References}

Akpede, G.O. \& Omotara, B.A. (1997) Oral rehydration at home with a little helps from friends. World Health Forum 18, 75-79.

Claeson, M. \& Merson, M.H. (1990) Global progress in the control of diarrhoeal Diseases. Journal of Pediatric Infectious Diseases 9, 345-355.

Dupont, H.L. (1997) Guidelines on acute diarrhoea in adults. The practice Parameters Committee of the American College of Gastroenterology. American Journal of Gastroenterology 92, 1962-1975.

Fekety, R. (1997) Guidelines for the diagnosis and management of Clostridium difficileassociated diarrhoea and colitis. American College of Gastroenterology, Practice Parameters Committee. American Journal of Gastroenterology 92, 739-750.

Gabr, M. (1983) Malnutrition and diarrhoeal disease. Diarrhoea Control Newsletter (1):3-4.

Gascón, J., Vargas, M., Schellenberg, D., Urassa, H., Casals, C., Kahigwa, E., Aponte, J.J., Mshinda, H. \& Vila, J. (2000) Diarrhoea in children under 5 years of age from Ifakara, Tanzania: a case-control study. Journal of Clinical Microbiology 38, 4459-4462.

Hamer, D.H., Simon, J., Thea, D., Keusch, G.T. (1998) Childhood diarrhoea in Sub-Saharan Africa. Child Health Research Project Special Report. World Health Organization Vol. 2(1).

HAI (2007) Monitoring Medicines in Tanzania. 2007 Report. Health Action International. Available at: www.haiweb.org/medicineprice.

Khalil, K., Lindblom, G.B., Mazhar, K., Khan, S.R. \& Kajiser, B. (2008) Early child health in Lahore, Pakistan: VIII Microbiology. Acta Paediatrica 82, 87-94.

Longstreth, G.L., Thompson, W.G., Chey, W.D., Houghton, L.A., Mearin, F. \& Spiller, R.C. (2006) Functional Bowel Disorders. Gastroenterology 130, 1480-1491 
MacGowan, A.P. (2008) Clinical implications of antimicrobial resistance for therapy. Journal of Antimicrobial Chemotherapy 62, 105-114.

Mahalanabis, D., Faruque AS, Islam A, Hoque SS. (1996) Maternal education and family income as determinants of severe disease following acute diarrhoea in children: A Case Control Study. Journal of Biosocial Science 28, 129-139.

Mandomando, M.I, Macete, E.V., Ruiz, J., Abacassamo, F., Valles, X., Sacarlal, J., Navia, M.M., Vila, J., Alonso, P.L. \& Gascon, J. (2007) Etiology of diarrhoea in children younger than 5 years of age admitted in a rural hospital of Southern Mozambique. American Journal of Tropical Medicine and Hygiene 76, 522-527.

Mujibur, R.M., Mitra, A.K., Mahalanabis, D., Wahed, M.A., Khatun, M. \& Majid,N. (1997) Absorption of nutrients from an energy-dense diet liquefied with amylase from germinated wheat in infants with acute diarrhoea. Journal of Paediatric Gastroenterology and Nutrition 24, 119-123.

Scheidler, M.D. \& Giannella, R.A. (2001) Practical management of acute diarrhoea. Hospital Practice 36, 49-56.

Shangali, C.F., Zilihon, I.J. E., Mwang'ingo, P.L.P., \& Nummelin, M. (2008) Use of Medicinal Plants in the Eastern Arc Mountains with special reference to the Hehe ethnic group in the Udzungwa Mountains, Tanzania. Journal of East African Natural History 97, 225254.

Snyder, J.D. \& Merson, M.H. (1982) The magnitude of the global problem of acute diarrhoeal disease: a review of active surveillance data. Bulletin of the World Health Organization 60, 605-613.

WHO (1997) Division of Child Health and Development. IMCI research priorities: examining methods to prevent and manage childhood illness. Geneva: WHO (June 1997 IMCI Information).

WHO (2000) Water and Sanitation. Global Water Supply and Sanitation Assessment, 2000 Report. WHO \& NICEF/WSSCC. Available at www.who.int/water sanitation. (Last access February 2009).

Young, B. \& Briscoe, J. (1987) A case control study of the effect of environmental sanitation on diarrhoea morbidity in Malawi. Journal of Epidemiology and Community Health 42, 83-88.

Zodpey, S.P., Deshpande, S.G., Ughade, S.N., Hinge, A.V. \& Shirikhande, S.N. (1998) Risk factors for development of dehydration in underfives children who have acute watery diarrhoea: a case control study. Public Health 112: 233-236. 